\title{
THE DETERMINATION OF CARBON, HYDKOGEN AND NITROGEN IN ORGANIC BODIES BY ONE COMBUSTION ONLY.
}

\section{Paul Jamnasch and Victor Meyer.*}

THE process which we are now bringing to the notice of analysts is not intended to supersede the present ones, as these are very satisfactory and expeditious, though requiring two combustions and consequently two separate portions of the substance to be analysed. Once, however, we had to analyse a nitrogenous body of which there was only $\cdot 1$ gram. at our disposal, consequently too little for a complete analysis, and were induced to work out a process which would require only one combustion. The principle of our process is as follows:-

The combustion is carried out in a combustion tube, with cupric oxide and metallic copper in front. The tube is connected as usual with a weighed chloride of calcium tube and potash bulbs, also with a flask to collect the nitrogen. In the combustion by Dumas' process the air from the tube is expelled by a current of carbonic acid, but in our process by a current of oxygen. Instead of collecting the nitrogen over potash ley it is collected over a solution of chromous chloride, which has the property of absorbing oxygen as rapidly as potash absorbs carbonic acid. The process, ;which seems so easy in principle, offered many difficulties in practice which we have only lately overcome. The chief trouble was to find a proper source of oxygen. We will not mention the many failures we experienced in this direction, sufficient to say we found potassium chlorate and manganic dioxide, of no use whatever; also failed when wo passed oxygen from a gasometer. A splendid source of oxygen is a mixture of potassium permanganate and potassium dichromate, which when heated inside the tube causes a very 
regular current of oxygen. By heating potassium permanganate alone, we also get pure oxygen, but at the same time form $\mathrm{K}_{2} \mathrm{O}$ which absorbs $\mathrm{CO}_{2}$. The acid chromate does not prevent a slight absorption at first, but gradually expels the carbonic acid, which finds its way to the weighed potash bulbs.

Another difficulty we at first experienced when analysing nitro-compounds was the incomplete reduction of nitric-oxide in presence of oxygen. The reduction was not complete even when we used a long layer of copper, or copper and silver spirals. This can be altogether avoided by operating in an atmosphere of oxygen, under low pressure. This is done by the following arrangement: The flask in which the $\mathrm{N}$ is to be collected is placed low and connected with the potash bulbs by means of a $90 \mathrm{Cm}$. long gas delivery tube. When all the air has been expelled, the supply of $O$ is temporarily stopped. A portion of the $O$ is absorbed by the hot copper, and another portion expelled the tube. The reduction of the nitric-oxide is now quite complete, because the combustion takes place in dilute oxygen.

The preparation of chromous chloride is very simple. We obtain from Dr. Schuchardt, in Görlitz, a paste of chromous acetate, which has only to be dissolved in $\mathrm{HCl}$ to at once yield a solution of chromous chloride. A small quantity of the acetate must be left undecomposed as free $\mathrm{HCl}$ gradually raises the chromous to the chromic state with evolution of hydrogen, which would contaminate the nitrogen. Before adding the acid we boil 50 grams. of the paste with $200 \mathrm{cc}$. of water in a flask which is then corked whilst still hot.

The combustion tube is $1.2 \mathrm{M}$ long, drawn out to a straight point, and is charged as follows:-First a little ignited asbestos, then a $20 \mathrm{Cm}$. long layer of the oxygen mixture, then $4 \mathrm{Cm}$. asbestos, $10 \mathrm{Cm}$. copper spirals, again $12 \mathrm{Cm}$. copper oxide. Then the substance to be analysed, either in a boat or mixed with a little copper oxide, then another $22 \mathrm{Cm}$. copper oxide and two layers of metallic copper $10 \mathrm{Cm}$. each, again $20 \mathrm{Cm}$. of oxide, then asbestos. The calcium chloride tube must be without corks. The ley in the potash apparatus (Geisslers) must be concentrated (50 per cent.), and care must bo taken not to overfill the bulbs. Before the gas enters the delivery tube we pass it through a second small tube filled with $\mathrm{KHO}$, but this need not be weighed. For collecting the nitrogen we prefirr to use a round flask of 400 cc. capacity, with a neck $30 \mathrm{Cm}$. long and $1.6 \mathrm{Cm}$. wide. This enables us to shake the contents better than we could do with the usual narrow apparatus, and so we assist the absorption of the oxygen. The nitrogen can easily be transferred to an ordinary measuring tube filled with water. The mixed oxygen and nitrogen onter the delivery tube and pass through mercury into the solution of the chromous chloride.

The oxygen generating mixture is composed of 110 grams. of potassium di-chromate and 100 grams. of potassium permanganate. Before use it must be dried for two hours at a temperature not exceeding $140^{\circ} \mathrm{C}$ and cooled under a dessicator. After having wired the india-rubber connections we now fill the tube with oxygen, which is passed from a gasometer through the drawn out part of the tube for 10 minutes. We now

\footnotetext{
* To prevent nitric oxide from acting on the permanganate.
} 
seal the point and apply heat to the $O$ mixture to fill the apparatus with perfectly pure oxygen. Heat is applied to only one half of the mixture for 20 minutes, which will keep up a regular current of 0 . Whilst this is going on, the chrome solution is prepared as follows :-200 ec. of mercury are put into the flask, then the boiled chromous acetate, then $60 \mathrm{cc}$. of a mixture of 1 part of fuming $\mathrm{HCl}$ and 3 parts of water. Enough water is now added to completely fill the flask, which is then at once inverted over mercury. When perfectly pure oxygen passes from the tube the heat is removed, and when no more bubbles of $O$ escape, the inverted flask is placed over the delivery tube.

We now heat the two front layers of metallic copper and copper oxide to redness, which causes some of the $O$ to escape from the tube and another portion to combine with the metallic copper. The combustion of the substance is now carried on as usual, but the pressure inside being low, care must be taken not to apply too strong a heat, as this would soften the tube. When no more gas is given off, fresh oxygen must be evolved. Soon after this heat is withdrawn from the first and the last copper spirals, but the copper in the centre is kept red hot until all the reduced $\mathrm{CuO}$ is again completely oxidised. The current of $O$ must not be too rapid at first to ensure complete absorption of $\mathrm{CO}_{2}$, but must afterwards be quickened to expel all the $\mathrm{N}$. The absorption of the $\mathrm{O}$ by the chrome solution is favoured by often gently shaking the flask. After 10 minutes the flask is removed, and, to ensure the complete expulsion of the $\mathrm{CO}_{2}$, the oxygen mixture is heated to redness, whilst the other part of the tube is allowed to cool.

Finally, whilst the permanganate is still hot,air (free from $\mathrm{CO}_{2}$ and $\mathrm{H}_{2} \mathrm{O}$ ) is drawn through the apparatus to expel the oxygen. The calcium chloride tubes and the potash apparatus are now reweighed and the carbon and hydrogen calculated. The nitrogen, which must not be left too long in contact with the chrome solution, as free hydrogen will be evolved after some hours, is transferred, in usual manner, to an accurate gas measuring tube and measured moist.

Test Analyses.-Acetaniliti.

.2364 grm. yielded $\cdot 6168 \mathrm{CO}_{2}=\cdot 168218 \mathrm{C} ; 1466 \mathrm{H}_{2} \mathrm{O}=\cdot 016288 \mathrm{H}$ and 22 cc. $\mathrm{N}$ at $14^{\circ} \mathrm{C}$ and $747 \mathrm{~mm}$. pressure $=\cdot 0254364 \mathrm{~N} . \quad 2694 \mathrm{grm}$. yielded $\cdot 7036 \mathrm{CO}_{2}=\cdot 191891 \mathrm{C} . ; \cdot 1687$

$\mathrm{H}_{2} \mathrm{O}=\cdot 018744 \mathrm{H}$. and 25 cc. $\mathrm{N}$. at $14^{\prime \prime} \mathrm{C}$ and $738 \mathrm{~mm}$. pressure $=\cdot 028550 \mathrm{~N}$.

Theory.

Found.

$\begin{array}{rrrr}\mathrm{C} & 71.11 & 71.15 & 71.23 \\ \mathrm{H} & 6.66 & 6.89 & 6.95 \\ \mathrm{~N} & 10.37 & 10.75 & 10.59\end{array}$

AZOBENZOL.

$\cdot 2362=\cdot 687 \mathrm{CO}_{2}=\cdot 187364 \mathrm{C}$; $\cdot 1256 \mathrm{H}_{2} \mathrm{O}=\cdot 013955 \mathrm{H}$ and $31 \mathrm{cc}$. N. at $12^{\circ} \mathrm{O}$ and 737 m.m. pressure $=\cdot 0356717 \mathrm{~N} . \cdot 226=\cdot 6542 \mathrm{CO}_{2}=\cdot 178418 \mathrm{C} ; \cdot 1166 \mathrm{H}_{2} \mathrm{O}=\cdot 012955 \mathrm{H}$ and 29.9 cc. $\mathrm{N}$ at $14^{\prime \prime} \mathrm{C}$ and $751 \mathrm{~mm}$. pressure $=.03475875 \mathrm{~N}$.

Theory.

(C) $79 \cdot 12$

H 5.49

Found.

N 15.39

$79 \cdot 32$

$78 \cdot 94$

$5 \cdot 91$

5.73

$15 \cdot 10$

$15 \cdot 38$ 


\section{DINITROBENZOL.}

$\cdot 2334=\cdot 3674 \mathrm{CO}_{2}=\cdot 10020 \mathrm{C} ; \cdot 0543 \mathrm{H}_{2} \mathrm{O}=\cdot 0060333 \mathrm{H}$ and 33 cc. $\mathrm{N}$ at $14^{\circ} \mathrm{C}$ and 742 mm. pressure $=\cdot 0378939 \mathrm{~N}$.

$\cdot 2415=\cdot 3756 \mathrm{CO}_{2}=.102436 \mathrm{C} ; \cdot 0569 \mathrm{H}_{2} \mathrm{O}=\cdot 0063222 \mathrm{H}$ and $35 \mathrm{cc} . \mathrm{N}$ at $14^{\circ} \mathrm{C}$ and 752 $\mathrm{mm}$. pressure $=\cdot 0407400 \mathrm{~N}$.

$\cdot 2374=\cdot 3748 \mathrm{CO}_{2}=\cdot 102218 \mathrm{C} ; \cdot 0556 \mathrm{H}_{2} \mathrm{O}=\cdot 0061777 \mathrm{H}$ and $34 \cdot 5 \mathrm{cc} . \mathrm{N}$ at $12^{\circ} \mathrm{C}$ and 743 $\mathrm{mm}$. pressure $=\cdot 0400269 \mathrm{~N}$.

Theory.

C $42 \cdot 86$

Found.

H $2 \cdot 38$

42.93

$42 \cdot 42$

$43 \cdot 05$

N 16.67

2.58

$2 \cdot 62$

$16 \cdot 87$

$2 \cdot 60$

$16 \cdot 86$

L. DE K. 